\title{
Los filósofos terrenales. Vida, tiempo e ideas de los grandes pensadores de la economía
}

\author{
Title: Los filósofos terrenales. Vida, tiempo e ideas de los grandes pensadores de la economía \\ Author: Heilbroner, Robert L. \\ Edición: Alianza Editorial, Madrid, 2015, 522 pp.
}

ISBN. 978-84-9104-033-0

Francisco CABRILLO

Universidad Complutense de Madrid

Es bien sabido que existen dos tradiciones en el estudio de la historia del pensamiento económico. La primera es la historia del análisis económico que, como explicó Schumpeter en la introducción de su gran obra, que lleva precisamente este título, consiste en el estudio de los esfuerzos intelectuales que han realizado los hombres con el objeto de entender los fenómenos económicos o, lo que viene a ser lo mismo, la historia del análisis de los aspectos científicos del pensamiento económico. La segunda, la historia de las doctrinas económicas, tiene un contenido más amplio e intenta relacionar las aportaciones de cada uno de los autores estudiados tanto con la situación económica del país y el momento en el que les tocó vivir como con las ideas sociales y políticas de la época. Cada libro de historia del pensamiento económico se aproxima, más o menos, a uno de estos dos modelos; y, como muestra el ejemplo del propio Schumpeter, optar formalmente por uno de los métodos al principio de la obra no implica necesariamente que aquél se vaya a seguir en el desarrollo de ésta.

Los filósofos terrenales es un ejemplo evidente de la historia de las doctrinas económicas en el sentido más amplio del término, como el mismo título indica y como pone de manifiesto, de forma aún más clara, el subtítulo: "Vida, tiempo e ideas de los grandes pensadores de la economía". En el texto el lector encuentra referencias, sin duda, a las aportaciones que a la ciencia económica hizo cada uno de los autores seleccionados. Pero estas aportaciones no son las protagonistas del libro. Más importante es el mundo en el que estos hombres y vivieron y la forma en la que lo interpretaron y, en muchos casos, trataron de transformarlo.

¿Quiénes fueron estos grandes pensadores? El período que se estudia abarca desde los años centrales del siglo XVIII a mediados del siglo XX -la primera edición del libro se publicó en 1953-, si bien hay un capítulo introductorio dedicado al mundo anterior a Adam Smith y un breve texto final en el que el autor reflexiona sobre la evolución de la economía en la segunda mitad del siglo pasado, que se incorporó en ediciones posteriores del libro -la última revisada por el autor se publicó en 1999-. La delimitación temporal del estudio puede ser criticada, ciertamente; pero es muy razonable. Muchas historias de la economía empiezan con la obra de Smith y llegan hasta el momento en el que el autor termina su trabajo. Más discutible es, sin embargo, la selección de los autores y, en especial, el peso que se atribuye a cada uno de ellos.

Para situar esta obra en su contexto es interesante señalar que Robert Heilbroner fue un economista cuya carrera estuvo ligada estrechamente a la New School of Social Research. Este centro había sido creado en Nueva York en el año 1919, como una institución "progresista", en el sentido que este término tuvo en las ciencias sociales norteamericanas en las décadas iniciales del siglo XX. En los años treinta la escuela llegó a ser conocida como la "universidad del exilio", por el número significativo de profesores que se integraron en ella tras haber tenido que abandonar Europa central, bien por sus orígenes judíos, bien por sus ideas izquierdistas. Heilbroner, que había estudiado en Harvard inmediatamente antes de la Segunda Guerra Mundial, entró en la escuela en los años cincuenta como investigador y se doctoró en el mismo centro. Nombrado catedrático en 1971, permaneció en la escuela hasta su jubilación; y muchos de los principios de la institución se reflejan claramente en su forma de entender la economía.

Los filósofos terrenales es una obra de juventud, publicada cuando su autor tenía treinta y cuatro años y, que con el paso del tiempo, se convertiría en el segundo libro de economía más 
vendido en el mundo, sólo por detrás del manual de Samuelson. La obra está muy bien escrita y muestra la capacidad de su autor para llegar al gran público. Pero su contenido y su estructura nos plantean algunas dudas a los economistas. En primer lugar, el estudio de algunos autores no parece situarse siempre en el contexto adecuado. Por poner un solo ejemplo, no se entiende bienpor qué John Stuart Mill es analizado en el capítulo de los socialistas utópicos y no como un economista clásico, que desarrolló muchas ideas de Ricardo. Es cierto que se ocupó -y en ocasiones con bastante simpatía- del pensamiento socialista. Pero convendría dejar claro al lector que sus raíces ricardianas son mucho más importantes en su obra que sus posibles inclinaciones socialistas. Y su distinción entre las leyes de la producción y la distribución es mucho más un precedente de la economía del bienestar y de la socialdemocracia moderna que de los utópicos de su época.

Pero el capítulo más sorprendente es, seguramente, el séptimo, que se titula "El mundo victoriano y la economía alternativa". Colocado inmediatamente a continuación del capítulo dedicado a Marx, en él se mezclan cosas tan dispares como el pensamiento neoclásico del último tercio del siglo XIX, la obra de un liberal radical como Bastiat y las ideas de autores como Hobson o Henry George que, curiosamente, Heilbroner consideraba más relevantes, por ejemplo, que Alfred Marshall. Por sorprendente que parezca, el autor de este libro pensaba que las contribuciones de economistas como Marshall, Jevons o J.B. Clark fueron importantes, "pero no esenciales" (sic). En realidad, todo el pensamiento neoclásico se presenta como un planteamiento ideológico dirigido a justificar el sistema económico de la época. Marx quedaba excluido del mundo de la teoría económica "porque su doctrina no agradaba" (sic). Y la interpretación que se presenta al final del capítulo del papel del pensamiento neoclásico en la evolución de la economía es tan dramática como criticable. Escribía Heilbroner: "La complacencia del mundo oficial no fue solamente un triste comentario sobre su época, sino también una tragedia intelectual de primer orden. Si los académicos hubieran prestado atención a los economistas alternativos, si Alfred Marshall hubiera tenido la perturbadora visión de un Hobson o de un Edgeworth o el sentido del error social de un Henry George, tal vez la gran catástrofe del siglo XX no se habría abatido sobre un mundo no preparado para un cambio social tan radical". Ante este texto, al lector le surge una pregunta: ¿sabía realmente Heilbroner teoría económica? Es evidente que el libro se centra en la vida y el mundo de los economistas y no en un análisis de sus teorías. Pero cabe argumentar que un buen conocimiento de la evolución de la ciencia económica a lo largo de los dos últimos siglos habría ayudado a dar solidez a la obra.

Otros autores tienen para Heilbroner, sin duda, mucho mayor atractivo que Marshall o los neoclásicos. Y Marx es uno de ellos. En sus propias palabras, es posible que Marx no fuera "infalible" en sus predicciones, pero es "imprescindible" aun en nuestros días, como lo son la obra de Platón ode Freud. Estos elogios a Marx y el hecho de poner su obra, de alguna manera, en relación con la de Platón y la de Freud traen a la mente a una de las grandes figuras de la filosofía del siglo XX, Karl Popper. Este se ocupó, en efecto, de las obras de Platón y de Marx en La sociedad abierta y sus enemigos y mostró que su mensaje -su filosofía terrenal, en el lenguaje de Heilbroner- es contraria a los principios de una sociedad libre y próspera. Y, desde el punto de vista de la filosofía de la ciencia, consideró las teorías de Marx y de Freud como ejemplo de teorías no científicas en cuanto no contienen proposiciones contrastables y falsables, y son capaces de explicar casi cualquier cosa mediante la introducción de hipótesis ad hoc.

Pero Heilbroner va, incluso, más allá cuando analiza la obra de Marx. En su opinión, ésta no es sólo importante por haber creado un gran sistema explicativo de la dinámica de la historia, y del desarrollo del capitalismo en particular; también lo es porque, en sus propias palabras, Marx fue un "gran economista". Y esto es, ciertamente, bastante discutible; y no sólo porque el problema de la transformación de valores en precios esté mal resuelto en El capital. Es que la teoría de la plusvalía -el concepto fundamental de su análisis económico- tiene muy poco sentido. Tal vez la conocida frase - un tanto despectiva- de Samuelson, de acuerdo con la cual Marx fue un "ricardiano menor", resulte exagerada. Pero aceptar la idea de que Marx fue un gran economista requiere hoy esfuerzos bastante heroicos.

Las ideas de Heilbroner fueron evolucionando, lógicamente, a lo largo del tiempo y parece que, al final de su vida, y tras haber sido testigo del colapso de la Unión Soviética, reconoció, de forma abierta, la superioridad del sistema capitalista sobre el socialista. Pero su capitalismo 
exigía una importante intervención del Estado en la economía; y en su libro queda patente la gran admiración que sintió por Keynes a lo largo de toda su vida. El mensaje es simple: Keynes sabía mucha más economía que cualquier otra persona en su época y, además, tenía razón en sus críticas a casi todo lo que se escribió con anterioridad a él. Y nada ha habido después superior a su obra: "quienes han insistido en calificar a Keynes de irritante intruso en un sistema que funcionaba bastante bien no han propuesto una teoría más meditada, un diagnóstico más profundo ni un tratamiento más convincente que los suyos". Y su filosofía terrenal, la que realmente Heilbroner abraza, es una filosofía "pragmática", que reconoce al capitalismo como "el único sistema aplicable del que se dispone", pero que no puede funcionar satisfactoriamente sin una "fuerte presencia gubernamental".

La conclusión a la que lleva la lectura de este libro es ambivalente. Si se me preguntara si yo lo recomendaría a un estudiante de economía como una obra de introducción a la historia de su disciplina, mi respuesta sería negativa; y no solamente por mi desacuerdo con algunas de las ideas del autor. Más importante es que quien lee el libro sin conocimientos previos de la materia -y éste es el público al que, claramente, la obra se dirige- no obtiene una visión clara y sistemática de la evolución de las ideas económicas a lo largo del tiempo. Adam Smith, por ejemplo, no es considerado como uno de los grandes economistas de todos los tiempos sólo por la idea de que la economía funciona de una manera más o menos armónica, inspirada por el principio de la mano invisible, la tesis que en el libro se mantiene. So obra es además -al margen de su mayor o menor originalidad- el primer gran tratado de economía de la historia. Y muchas de sus ideas tienen validez universal y siguen siendo útiles en nuestros días, doscientos cuarenta años después de su publicación. Y comentarios similares podrían hacerse del tratamiento que en el libro se da a la obra de otros grandes economistas del pasado, a los que se sitúa en el medio ambiente histórico y cultural en el que se desenvolvieron, pero sin conseguir que el lector sepa muy bien por qué estos economistas -y no otros- fueron importantes. Y los argumentos de por qué Hobson, George o Veblen ocupan un papel tan destacado en el libro, plantean serias dudas a cualquier experto en la materia.

Por otro lado, sin embargo, esta obra puede resultar de gran utilidad en unos momentos en los que buena parte de los economistas tienen una ignorancia enciclopédica con respecto al origen de sus propias ideas y de las teorías que aplican en su actividad profesional. Y una visión global de lo que escribieron y pensaron los grandes economistas del pasado debería resultarles tan necesaria como interesante. El problema es que este libro no es, seguramente, la obra más adecuada para lograr este objetivo. 